\title{
Frictional Resistance in Vorious Ceramic Brackets using Archwires of different Alloys, Sizes and Cross sections: A Comparative Study
}

\author{
Dr Yash Raj Bahadur.' Dr Deepak Kumar Agarwal,2 Dr Ankur Gupta, ${ }^{3}$ Dr P Narayana Prasad4 \\ 'Senior Lecturer, ${ }^{4}$ Professor, Dept of Orthodontics, Seema Dental College, Rishikesh \\ ${ }^{2}$ Professor, ${ }^{3 R e a d e r}$, Dept of Orthodontics, Institute of Dental Sciences, Bareilly, India
}

Correspondence: Dr Yash Raj Bahadur; Email:dr.yash.ortho@gmail.com

\section{ABSTRACT}

Introduction: Friction at the bracket-archwire interface has been observed as one of the most important factors affecting tooth movement. Hence it is importance to assess the friction generated during tooth movement to bring about optimal treatment results.

Objective: To compare the frictional resistance of various ceramic brackets using different archwires, and to compare the static and kinetic frictional force of various ceramic brackets using different archwires.

Materials \& Method: The present study evaluated and compared the friction generated at the bracket archwire interface when $0.018^{\prime \prime}$ and 0.019 "x0.025" stainless steel archwires and 0.019 "x 0.025 " teflon coated stainless steel archwires were moved through conventionally ligated, passive self-ligating and interactive self-ligating ceramic brackets. The static and kinetic frictional forces were also evaluated and compared.

Result: Highly significant differences in kinetic $(p<0.001)$ and static $(p<0.001)$ frictional forces were observed in all three groups when used with the different archwires. On comparing the static and kinetic frictional forces significant differences were observed among all three groups $(p<0.05)$.

Conclusion: The passive self-ligating brackets produce the least frictional forces when compared to interactive self-ligating and conventionally ligated brackets. Also, the static frictional forces were found to be more as compared to kinetic frictional forces

Key words: archwire, ceramic brackets, friction, self-ligating bracket

\section{INTRODUCTION}

Friction is defined as a force tangential to the common boundary of two bodies in contact that resists the motion or tendency to motion of one relative to the other.' It exists in two forms: static friction, which is the resistance that prevents actual motion, and dynamic (kinetic) friction, which exists during motion. ${ }^{2}$

The efficiency of fixed appliance therapy depends on the fraction of force delivered with respect to the force applied; hence, high frictional forces due to the interaction between the bracket and the guiding archwire affect treatment outcomes and duration in a negative manner. ${ }^{3}$ When sliding mechanics are used, friction occurs at the bracket-wire interface. Some of the applied force is therefore dissipated as friction, and the remainder is transferred to supporting structures of the tooth to mediate tooth movement. ${ }^{4}$

Schumacher et al stated that friction is determined mostly by nature of ligation. Self-ligating brackets were introduced in the mid-1930s in the form of Russell attachment. Selfligating brackets are ligatureless bracket systems that have a mechanical device built into the bracket to close the slot. ${ }^{5}$

Self-ligating brackets can be classified as active or passive; based on the mode of self-ligation. Active appliances have a spring clip that functions as the fourth wall of the bracket slot, hence making positive contact with the archwire. Passive appliances have a movable labial side that creates a hollow tube inside the bracket during closure. ${ }^{6}$

Contemporary orthodontics provides service to great number of adults, especially women, thus the need for optimum cosmetic appearance of orthodontic appliances has been emphasized. As a result, ceramic brackets were introduction in 1986. ${ }^{7}$ Thus the present study was conducted to compare the frictional forces between various ceramic brackets and archwires and also to compare the static and kinetic frictional forces respectively. 


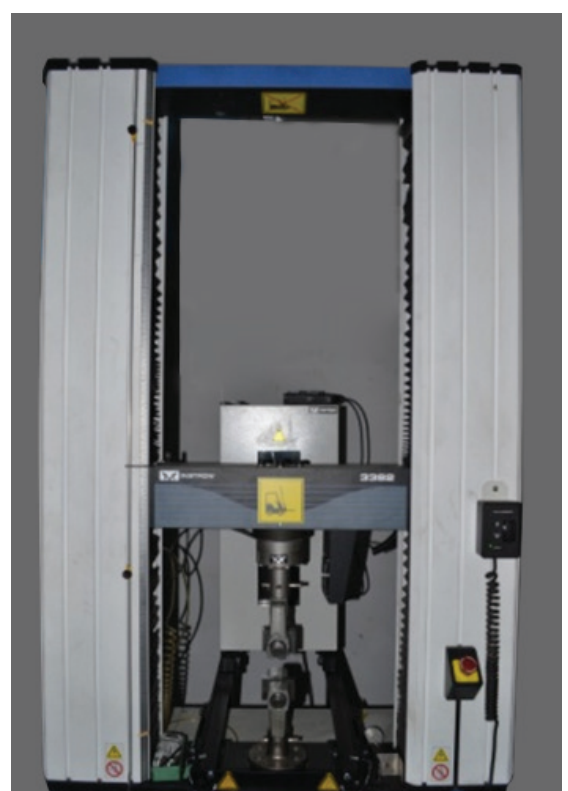

Figure 1: Universal Testing Machine (Instron)

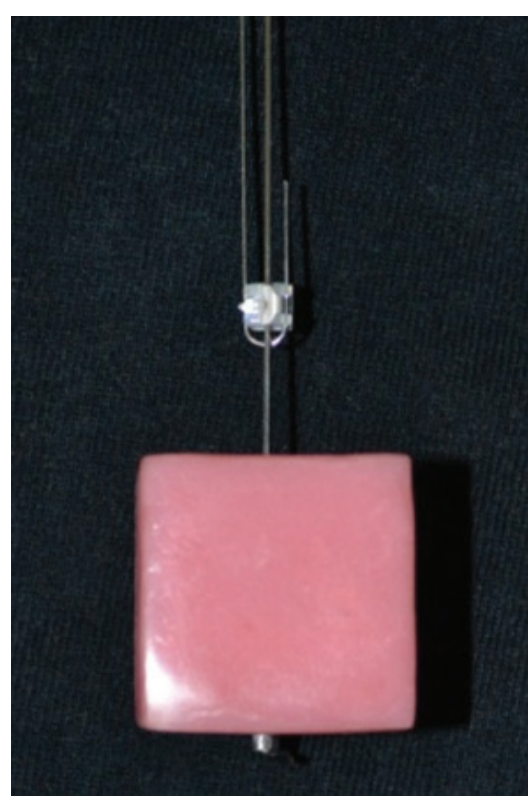

Figure 2: Custom made apparatus with test sample

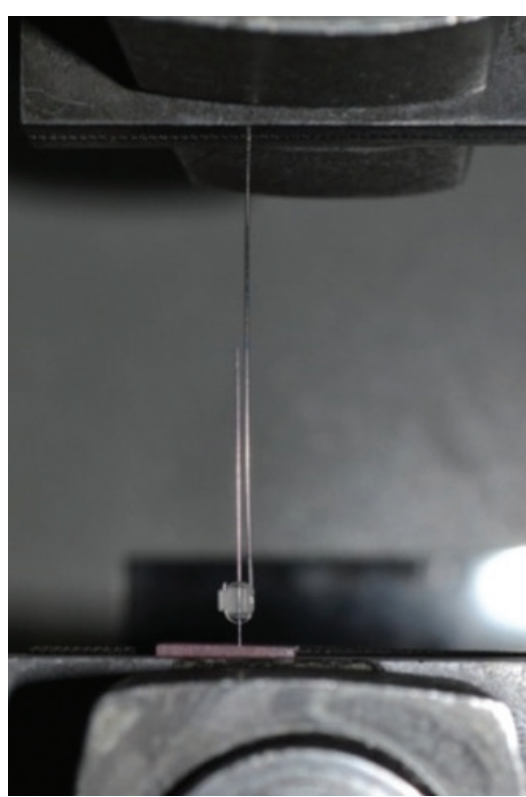

Figure 3: Test sample attached to Instron machine

\section{MATERIALS AND METHOD}

The present study was performed to evaluate the friction between different types of orthodontic ceramic brackets and wire of different sizes, cross-sections and alloys in the Department of Orthodontics, Institute of Dental Sciences, Bareilly in association with Northern India Textile Research Association, Ghaziabad.

All testing was done on Universal Testing Machine (Instron) (Figure 1). The study consisted of eight millimeter long 0.018 "stainless steel (3M Unitek), 0.019"x0.025" stainless steel (3M Unitek) and 0.019"x0.025" Teflon coated stainless steel (Spectra, GAC Dentsply) working archwires which were moved through three types of maxillary premolar brackets which were grouped as:

Group 1 : Interactive self-ligating ceramic bracket (InOvation C, GAC Dentsply)

Group 2 : Passive self-ligating ceramic bracket (Damon Clear, Ormco)

Group 3 : Conventionally ligated ceramic bracket (Transcend, 3M Unitek)

The brackets and archwires were cleaned with alcohol wipe before performing the tests. Lower end of each test unit was attached to a custom made apparatus which was itself attached to the lower jaw of the testing machine. The custom made apparatus was made as a heavy acrylic block $(20 \mathrm{~mm}$ length $\times 20 \mathrm{~mm}$ width $\times 20 \mathrm{~mm}$ height) with a hollow sheath (having 0.036 " diameter and $21 \mathrm{~mm}$ length), which was constructed to hold the wire parallel to the vertical framework of the universal Testing Machine (Figure 2). This apparatus was made to be free to undergo rotational movement by making a $2 \mathrm{~mm}$ right-angle bend in the archwire at the lower end. It was ensured that the bracket and archwire specimens could self-align during a test run, allowing tip and torque to be effectively eliminated as variables so that the effect of ligation method on friction could be studied in isolation. The sample was arranged parallel to the vertical framework of the machine. The bracket was then pulled in a vertical direction by a loop of 0.018 " stainless steel wire which was fixed at upper jaw of the machine (Figure 3). The force required for initiating and maintaining the movement of the bracket over an $8 \mathrm{~mm}$ test distance was recorded. Each bracket and archwire was used for 10 tests and after 10 tests the sample was changed. ${ }^{8}$

The static frictional force was measured as the initial rise or peak force required to initiate movement of the wire through the bracket and then halved. The drawing force required to maintain the movement beyond the point of initial displacement was averaged and then halved and recorded as the kinetic friction. Data were obtained at a rate of five readings per second. ${ }^{?}$

Descriptive statistics were determined for all groups, which were used for comparison between the groups. The data obtained were analyzed using MS Excel and SPSS. The comparison of data obtained for various bracket archwire ligature groups was done by Kruskal-Wallis $\mathrm{H}$ test and Wilcoxon signed rank test. The comparison of the frictional forces between the three groups was done using KruskalWallis $\mathrm{H}$ test. 
Table 1: Comparison of kinetic frictional force between three groups

\begin{tabular}{|c|c|c|c|c|c|c|}
\hline \multirow{3}{*}{ Brackets } & \multicolumn{6}{|c|}{ Archwires } \\
\hline & \multicolumn{2}{|c|}{$0.018 "$ SS } & \multicolumn{2}{|c|}{$0.019 " \times 0.025 "$ SS } & \multicolumn{2}{|c|}{$0.019 \times 0.025$ " teflon coated SS } \\
\hline & Mean (gm) & SD & Mean (gm) & SD & Mean (gm) & SD \\
\hline Group 1 & 0 & 0 & 43.4 & 4.04 & 32.39 & 9.27 \\
\hline Group 2 & 0 & 0 & 3.58 & 2.38 & 3.35 & 2.1 \\
\hline Group 3 & 37.92 & 7.23 & 83.37 & 8.54 & 65.81 & 7.27 \\
\hline $\begin{array}{l}1 \text { Vs } 2 \text { Vs } 3 \\
\text { (Kruskal Wallis H test) }\end{array}$ & \multicolumn{2}{|c|}{$\begin{array}{l}2 \text { groups empty, } \\
\text { test not performed }\end{array}$} & \multicolumn{2}{|c|}{$H(2)=123.373, d f=18, p=0.00^{*}$} & \multicolumn{2}{|c|}{$H(2)=117.828, d f=18, p=0.00^{*}$} \\
\hline
\end{tabular}

*Statistically significant at $p<0.05$

\section{RESULT}

Comparison of static frictional forces among three groups showed highly significant differences with the maximum static frictional forces being generated in conventionally ligated ceramic and the least being produced in passive self-ligating ceramic brackets. Both the ceramic self-ligating brackets showed no static frictional forces in conjunction with 0.018 " stainless steel wires (Table 2). Similar results were observed when the kinetic frictional forces were evaluated (Table 1).

Comparison of the static and kinetic frictional forces in each of the three groups showed significant differences in all groups with the static frictional force being more in comparison to the kinetic frictional forces (Graph 1,2,3).

\section{DISCUSSION}

Friction is the force that resists the movement of one surface past another and acts in a direction opposite the direction of movement. It is a function of the relative roughness of two surfaces in contact. ${ }^{10}$ Frictional force has two components; the initial friction between the arch wire and the bracket when a force is applied is termed as static friction and must be overcome to initiate tooth movement. As the tooth is moving, the second component to friction termed kinetic friction occurs with the arch wire moving in the direction of the applied force as it is guided through the molar and premolar bracket slots."

Ceramic brackets were introduced in orthodontics to meet increasing aesthetic demand, along with concerns about the effect of corrosion and reaction to Nickel that leaches out of stainless steel-based material in oral cavity. These brackets are aesthetically superior and more biocompatible in nature. ${ }^{12}$

The present day scenario in orthodontics emphasizes the aesthetic utility of ceramic brackets. However, the increased frictional resistance generated by ceramic brackets diminishes its effectiveness in clinical use. Hence the ceramic self-ligating brackets were introduced to combine the superior aesthetics of ceramic brackets with the reduced friction of self-ligating brackets. ${ }^{13}$

The 0.018 " round and 0.019 "x0.025" rectangular wires are used in the present study to assess the effect of wires of different cross-sections and sizes on the frictional forces generated in different brackets. Earlier the stainless steel wires were the mainstay for orthodontic usage, but the aesthetic concerns have resulted in the evolution of newer aesthetic wires. Teflon or polytetrafluoroethylene is a material characterized by a completely fluoridated chain. It is an anti-adherent and aesthetic material that has excellent chemical inertia as well as good mechanical stability. ${ }^{14}$

In the present study, when considering the 0.018" SS archwire, no frictional forces were generated with Group 1 and 2 whereas considerable static and kinetic frictional forces were generated with Group 3. Our findings are in agreement with studies conducted by Farronato et al, ${ }^{14}$ Singh et $a,,^{15}$ Brauchli et al ${ }^{16}$ who stated that the active and interactive self-ligating brackets did not demonstrate any frictional forces with 0.018 " SS wires and their conventional counterparts generated considerable frictional forces.

Table 2: Comparison of static frictional force between three groups

\begin{tabular}{|c|c|c|c|c|c|c|}
\hline \multirow{3}{*}{ Brackets } & \multicolumn{6}{|c|}{ Archwires } \\
\hline & \multicolumn{2}{|c|}{$0.018 "$ sS } & \multicolumn{2}{|c|}{$0.019 " \times 0.025 "$ SS } & \multicolumn{2}{|c|}{$0.019 \times 0.025$ " teflon coated SS } \\
\hline & Mean (gm) & SD & Mean (gm) & SD & Mean (gm) & SD \\
\hline Group 1 & 0 & 0 & 45.87 & 3.92 & 34.09 & 3.62 \\
\hline Group 2 & 0 & 0 & 5.9 & 2.24 & 5.31 & 2.19 \\
\hline Group 3 & 39.4 & 3.71 & 85.16 & 4.34 & 68.01 & 3.96 \\
\hline $\begin{array}{l}1 \text { Vs } 2 \text { Vs } 3 \\
\text { (Kruskal Wallis H test) }\end{array}$ & \multicolumn{2}{|c|}{$\begin{array}{l}2 \text { groups empty, } \\
\text { test not performed }\end{array}$} & \multicolumn{2}{|c|}{$H(2)=141.783, d f=18, p=0.00^{*}$} & \multicolumn{2}{|c|}{$H(2)=125.119, d f=18, p=0.00^{*}$} \\
\hline
\end{tabular}

*Statistically significant at $\mathrm{p}<0.05$ 
Group 2 demonstrated levels of friction that were considerably lower than that of the Group 1 during sliding mechanics with a 0.019 "x0.025" rectangular wire. The static and kinetic frictional forces exerted by Group 2 were minimal when compared to Group 1. Similarly the static and kinetic frictional forces exerted by Group 1 and 2 were lesser as compared to Group 3 in the present study. These results are in accordance with the studies conducted by Cacciafesta et $a l,{ }^{5}$ Stefanos et al, ${ }^{,}$Singh et $a l,{ }^{15}$ Brauchli et $a l,{ }^{16}$ Kannan et $a l,{ }^{17}$ Oliver et $a l,{ }^{18}$ Voudaris et $a l^{19}$ who stated that interactive self-ligating brackets have higher static and kinetic frictional forces compared to passive selfligating brackets when coupled with 0.019"x0.025" SS wires, which is lesser than that generated by the conventionally ligated brackets.
When frictional forces were assessed during sliding mechanics with 0.019 "x0.025" teflon coated stainless steel wire, it was found that, Group 2 demonstrated the least frictional force followed by Group 1. The maximum force was generated when Group 3 were used. These findings are in agreement with the findings reported by Farronato et $\mathrm{a}^{14}$ who reported that Teflon coated archwires produced lower frictional levels than their corresponding uncoated counterparts.

The friction values in 0.019"x0.025" SS archwires were more for all groups when compared to the values with 0.018 " SS wires. This finding confirms the studies of Singh et $a^{15}$ and Tecco ef $a^{20}$ that all brackets show higher frictional forces as the wire size is increased.

Graph 1: Comparison of static and kinetic frictional forces in Group 1

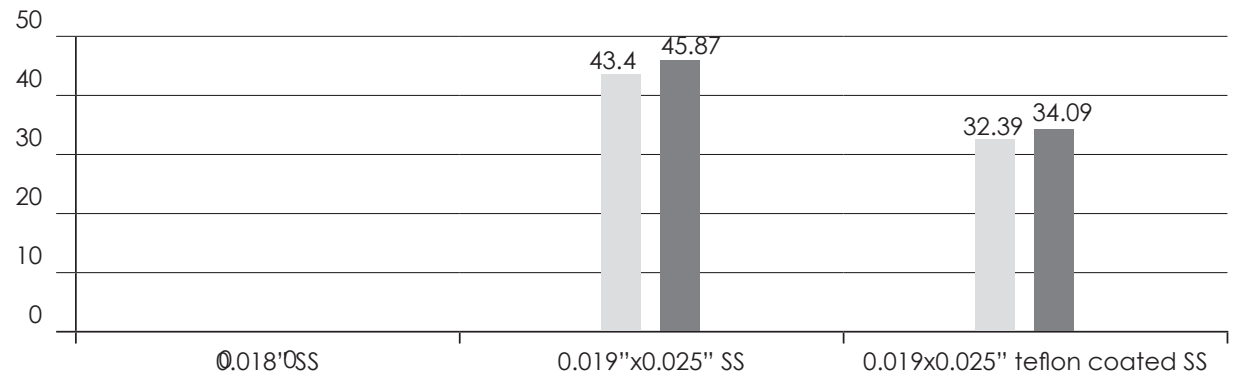

Graph 2: Comparison of static and kinetic frictional forces in Group 2

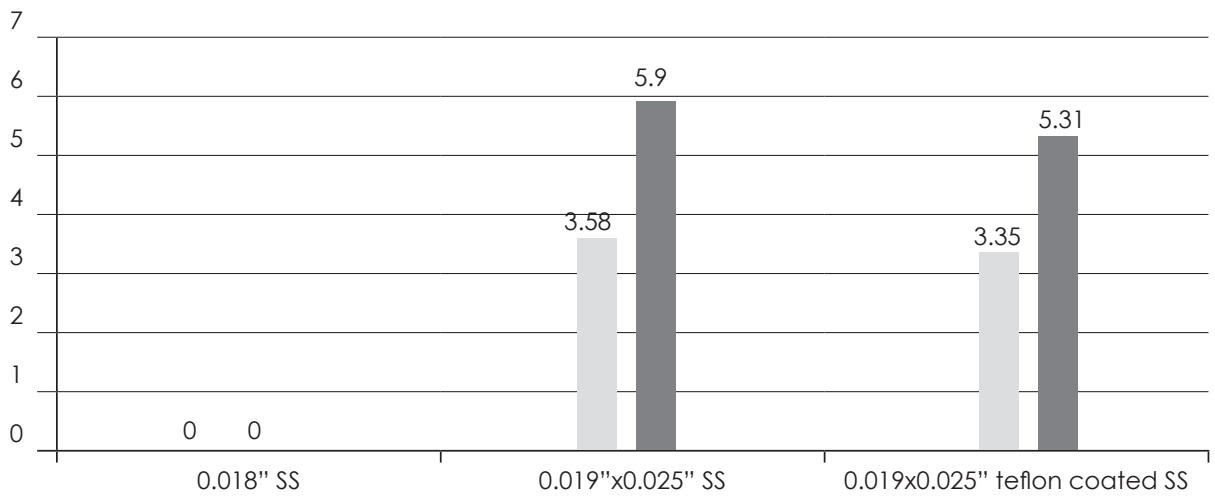

Graph 3: Comparison of static and kinetic frictional forces in Group 3

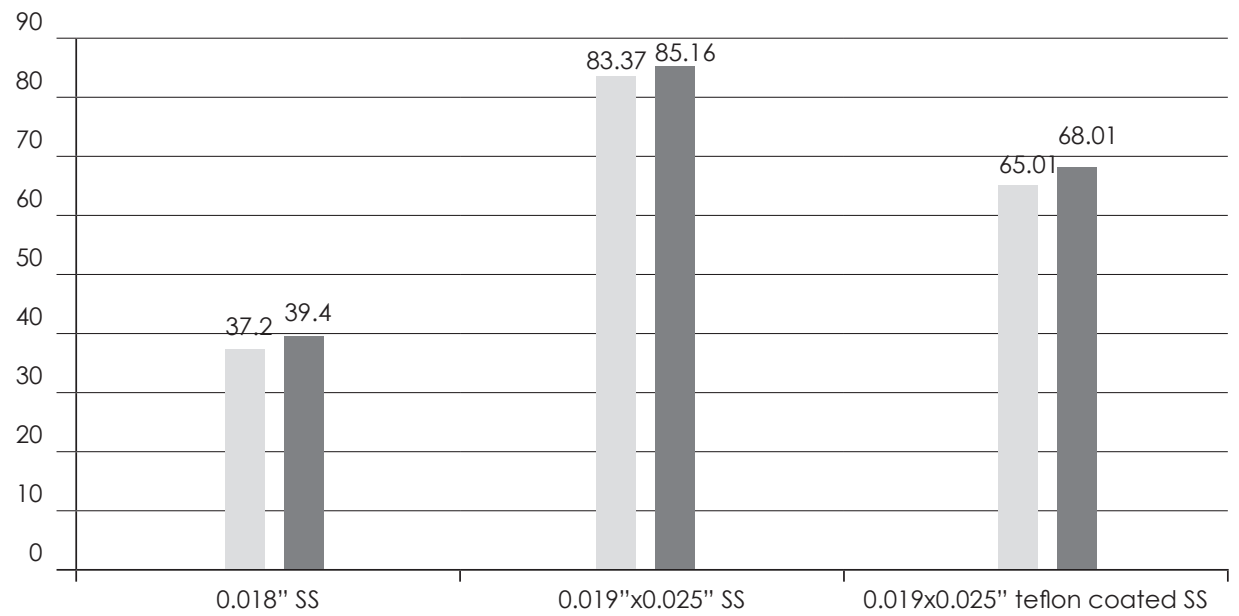


The present study showed that the static friction was higher than kinetic friction in all brackets and archwire combinations. Highly significant differences were seen in the results of the present study when comparing the static and kinetic frictional force in Group 1, Group 2 and Group 3. This is in accordance with the studies conducted by Cacciafesta et al, ${ }^{5}$ Krishnan

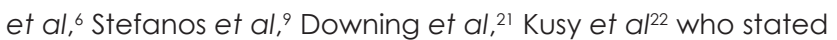
that the static friction is always greater than kinetic friction irrespective of the bracket or archwire combination used (Graph 1,2,3).

Since the present study was conducted in vitro, it has certain limitations. The test conditions may not really correspond to orthodontic tooth movement. Also the study was not designed to replicate the sliding mechanics according to the dental arch and the effect of saliva was not considered as no wet conditions were simulated.

\section{CONCLUSION}

The present study enables to conclude the following:

- Self-ligating brackets produce less friction as compared to conventionally ligating brackets. Passive self-ligating brackets produce lesser friction than interactive selfligating brackets.

- As the archwire size and cross-section changes, the frictional resistance also changes. When 0.018 " stainless steel wires are used with self-ligating brackets, no friction was generated and the frictional resistance increased when 0.019"x0.025" stainless steel wires are used.

- Static frictional force is always greater than kinetic friction, irrespective of bracket type or archwire used.

\section{REFERENCES}

1. Drescher D, Bourauel C, Schumacher HA. Frictional forces between bracket and arch wire. Am J Orthod Dentofacial Orthop. 1989: 96:397-404.

2. Tselepis $M$, Brockhurst $P$, West VC. The dynamic frictional resistance between orthodontic brackets and arch wires. Am J Orthod Dentofacial Orthop. 1994; 106:131-8.

3. Baccetti T, Franchi L. Friction produced by types of elastomeric ligatures in treatment mechanics with the preadjusted appliance. Angle Orthod. 2006; 76:211-6.

4. Nanda R, Gosh J. Biomechanical considerations in sliding mechanics. W.B. Saunders Company, 1996.

5. Cacciafesta V, Sfondrini MF, Ricciardi A, Scribante A, Klersy C, Auricchio F. Evaluation of friction of conventional and metal-insert ceramic brackets in various bracket-arch wire combinations. Am J Orthod Dentofacial Orthop. 2003; 124:403-9.

6. Krishnan M, Kalathil S, Abraham KM. Comparative evaluation of frictional forces in active and passive self-ligating brackets with various archwire alloys. Am J Orthod Dentofacial Orthop. 2009; 136:675-82.

7. Karamouzos A, Athanasiou A, Papadopoulos M. Clinical characteristics and properties of ceramic brackets: A comprehensive review. Am J Orthod Dentofacial Orthop. 1997; 112:34-40.

8. Hain M, Dhopatkar A, Rock P. The effect of ligation method on friction in sliding mechanics. Am J Orthod Dentofacial Orthop. 2003; 123:416-22.

9. Stefanos S, Secchi AG, Coby G, Tanna N, Mante FK. Friction between various self-ligating brackets and archwire couples during sliding mechanics. Am J Orthod Dentofacial Orthop 2010; 138:463-7.

10. Kapila S, Angolkar PV, Duncanson MG Jr., Nanada RS. Evaluation of friction between edgewise stainless steel brackets and orthodontic wires of four alloys. Am J Orthod Dentofacial Orthop. 1990; 98:117-26.

11. Bednar JR, Gruendeman GW. The influence of bracket design on moment production during axial rotation. Am J Orthod Dentofacial Orthop. 1993; 104:254-61.

12. Nishio C, Foneca A, Nelson J. In-vitro evaluation of frictional forces between arch wires and ceramic brackets, Am J Orthod Dentofacial Orthop. 2004; 125:56-64.

13. Oliver CL, Daskalogiannakis J, Tomson BD. Archwire depth is a significant parameter in the frictional resistance of active and interactive, but not passive self-ligating brackets. Angle Orthod. 2011; 81:1036-44.

14. Farronato G, Maijer R, Carì MP, Esposito L, Alberzoni D and Cacciatore G. The effect of Teflon coating on the resistance to sliding of orthodontic archwires. Eur J Orthod. 2012; 34:410-7.

15. Singh S, Hamsa PRR, Shetty P, Desai M. Comparison of friction between conventional and self-ligating brackets using various archwire combination: An in vitro study. Int J Dent Clinics. 2012; 4:27-31.

16. Brauchli LM, Senn C, Wichelhaus. Active and passive self-ligation: A myth? Angle Orthod. 2011; 81:312-8.

17. Kannan MS, Murali RV, Jayanth V, Annamalai PR. Comparison of frictional resistance of aesthetic and semi aesthetic self-ligating brackets. Ind J Multidisciplin Dent. 2012; 2:551-5.

18. Oliver CL, Daskalogiannakis J, Tomson BD. Archwire depth is a significant parameter in the frictional resistance of active and interactive, but not passive self-ligating brackets. Angle Orthod. 2011; 81:1036-44.

19. Voudaris JC, Schismenos C, Lackovic K, Kuftinec MM. Self-ligation aesthetic brackets with low frictional resistance. Angle Orthod. 2010; 80:188-94.

20. Tecco S, Festa F, Caputi S, Traini T, Di lorio D, D'Attilio M. Friction of conventional and self-ligating brackets using a 10 bracket model. Angle Orthod. 2005; 75:1041-5.

21. Downing A, McCabe J, Gordon P. A study of frictional forces between orthodontic brackets and archwires. Br J Orthod. $1994 ; 21: 349-57$.

22. Kusy RP, Whitley JQ. Friction between different wire-bracket configurations and materials. Semin Orthod 1997; 3:166-77. 